\title{
Developmental cognitive neuropsychology of number processing and calculation: varieties of developmental dyscalculia
}

\author{
von Aster, Michael
}

\begin{abstract}
This article provides a brief overview about the current state of cognitive developmental neuropsychology of developmental dyscalculia (DD) as well as results from a Zurich study that investigates different subtypes of DD according to various aspects of numerical abilities that are impaired or preserved. The differential effects of impairments of one particular numerical area on the development of other numerical abilities are highlighted in the case of a 17 year old boy with severe DD and Developmental Gerstmann Syndrome. A comprehensive model of developmental dynamics of number processing and calculation abilities will be proposed in the last section with respect to the development of intelligence theory
\end{abstract}

DOI: https://doi.org/10.1007/s007870070008

Posted at the Zurich Open Repository and Archive, University of Zurich ZORA URL: https://doi.org/10.5167/uzh-156088

Journal Article

Published Version

Originally published at:

von Aster, Michael (2000). Developmental cognitive neuropsychology of number processing and calculation: varieties of developmental dyscalculia. European Child Adolescent Psychiatry, 9(Suppl 2):II/41II $/ 57$.

DOI: https://doi.org/10.1007/s007870070008 


\section{Developmental cognitive neuropsychology of number processing and calculation: varieties of developmental dyscalculia}

\begin{abstract}
This article provides a brief overview about the current state of cognitive developmental neuropsychology of developmental dyscalculia (DD) as well as results from a Zurich study that investigates different subtypes of DD according to various aspects of numerical abilities that are impaired or preserved. The differential effects of impairments of one particular numerical area on the development of other numerical abilities are highlighted in the case of a 17 year old boy with
\end{abstract}

severe DD and Developmental Gerstmann Syndrome. A comprehensive model of developmental dynamics of number processing and calculation abilities will be proposed in the last section with respect to the development of intelligence theory.

Key words Number processing - calculation - development - information processing - developmental dyscalculia - subtypes - theory of intelligence

8708 Maennedorf/Zurich, Switzerland

E-mail: vonaster@kjpd.unizh.ch

\section{Introduction}

Current neuropsychological models postulate representational and format-specific modules, located in different areas of the left and the right cerebral hemisphere, that are relevant for adult cognitive number processing and calculation (15). The most widely discussed models are those of McCloskey and coworkers (43), the 'triple-code model' of Dehaene (12) and the encoding complex theory of Campbell and Clark (9). These models are based mainly on observations of dissociations and double dissociations in various aspects of number processing and calculation in adult subjects with brain trauma. Some particular specifications of these models remain controversial.

Taking these models to represent an 'end stage' of child development, the following paper will focus on the processes of suspected modularization and lateralization of different aspects of number processing, in other words, on the mean (or means) to that end stage and on possible bars and obstacles which may be encountered along the path(s). In addition to adults, very different kinds of difficulties in learning to manipulate numbers and acquiring arithmetic concepts have been observed in children. Several authors described subtypes of developmental dyscalculia (DD) and attempted to relate these specific cognitive impairments to maturational dysfunctions of distinct modules or particular regions of the developing brain $(24,41,51,66)$.

According to the International Classification of Diseases, $10^{\text {th }}$ revision (ICD-10, 74), and the Diagnostic and Statistical Manual of Mental Disorders, $4^{\text {th }}$ edition (DSM-IV, 2), the main defining criterion of DD is a significant discrepancy between specific mathematical abilities and general intelligence. Therefore, by definition, there is no major difference concerning general reasoning abilities between children of the same chronological age both with and without DD. However, comparing children with DD to children without, mathematical abilities in children with DD are at a level expected for normal children of lower chronological age. This implies that children with DD show a difference between their mental age and their chronological age concerning number processing and calculation abilities. The central role of psychometric intelligence in defining criteria for developmental disorders makes it necessary to take a closer look at modern theories of intelligence in 
order to provide a conceptual frame that could account for empirical findings from different relevant scientific domains.

The current developmental theory of intelligence that refers particularly to empirical findings on developmental disorders (i.e., dyslexia) is that by Mike Anderson (1). According to his theory, differences in the general cognitive performance [expressed as the intelligence quotient (IQ)] between children of the same chronological age ('within-age differences') are due to differences in basic information processing capacities which rely mainly on the speed of processing and remain stable over the course of development. However, differences in cognitive abilities between children of different chronological age ('between-age differences') are attributed to differences in the maturation of specific functional brain modules that emerge at certain stages of development and are either phylogenetically preformed or ontogenetically acquired through extensive practice according to contextual needs and environmental circumstances.

Anderson's theory of the 'minimal cognitive architecture' provides a useful framework for the synthesis of different, partly contradictory, findings concerning DD and other learning difficulties, and to account for the various genetic, gender-related and environmental (cultural, socio-emotional, instructional) influences that have been found to contribute to within-age and between-age differences in cognitive abilities in children.

The text of this paper is organized into four sections. In the first section, some essential empirical findings and current points of theoretical debate in cognitive neuropsychology concerning modularization and lateralization of number-related abilities will be summarized. The major ideas of Anderson's theory (1) and their potential to explain neuropsychological findings on DD are also highlighted. In the second and third sections, results of a group study and a single case study on DD will be presented and discussed. A comprehensive developmental model for number processing and calculation will be proposed in the last section and, conclusively, discussed with respect to the previous sections.

\section{Section 1: Developmental dyscalculia: deficient modularization and/or lateralization of number processing and calculation abilities?}

Dissociations, subtypes, patterns of cognitive functioning, localization

Evidence from functional brain-imaging studies have recently demonstrated that different aspects of complex cognitive abilities (i.e. language or number processing) are undoubtedly represented in different areas of the human brain. Furthermore, it could be demonstrated that the cortical representation of a certain ability varies with the time at which this ability is acquired. Kim et al. (36), for example, using functional magnetic resonance imaging, compared early and late bilingual subjects during language processing. In subjects who had acquired the second language after the age of 11 years ("late bilinguals'), there was a significant distance between the regions of the Broca area activated during language processing in the first and second language whereas, in bilingual subjects who had acquired the second language from the first years of life ('early bilinguals'), identical patterns of activation within the same area of the Broca area were demonstrated.

Dehaene et al. (13) studied functional brain activity patterns in adult subjects during different number-related tasks. They demonstrate that tasks requiring approximate calculations (i.e. $4+5=8$ or 3) showed a pattern of cortical activation with a maximum in the inferior parietal regions of both cerebral hemispheres. In contrast, during tasks that required exact calculation $(4+5=9$ or 7$)$, maximum activity was located in the left inferior prefrontal cortex.

Dehaene and colleagues (13) argue that these results support the theory for the existence of at least two of the three modules that constitute the triple code model (Fig. 1) for number processing (12), namely a module in which numbers are represented as number-words ('verbal word frame') and a module in which numbers are represented as an analogue locus on an internal number line ('analogue magnitude representation').

Within the triple-code model, abilities such as approximation and number comparison are attributed to the analogue module whereas abilities such as counting, the use of counting procedures in addition and subtraction and arithmetical fact retrieval are attributed to the verbal module. Multi-digit operations and parity judgements rely, according to this model, on a third module, the 'visual Arabic number form' in which numbers are represented by their Arabic code. These three modules constitute a system for number processing and calculation in which the modules are autonomous, interconnected and activated according to the particular needs of a given task.

Dissociations and double-dissociations of particular number processing and calculation abilities which have been extensively described in brain-damaged adults have only been reported in a few cases of children with DD. For instance, Temple (65) reported a developmental disorder of number processing termed 'digit dyslexia' in an 11-year-old boy who had age-appropriate reading and spelling skills but was unable to read Arabic numbers or write dictated Arabic numbers correctly. Furthermore, he was unable to read and write number-words correctly despite otherwise good reading skills, indicating the existence of independent modules for lexical and syntactical processing of Arabic as well as written and spoken numbers. Other case reports on children who performed well on reading and writing numbers in different formats but 
Fig. 1 The triple-code model for numerical cognition (12).

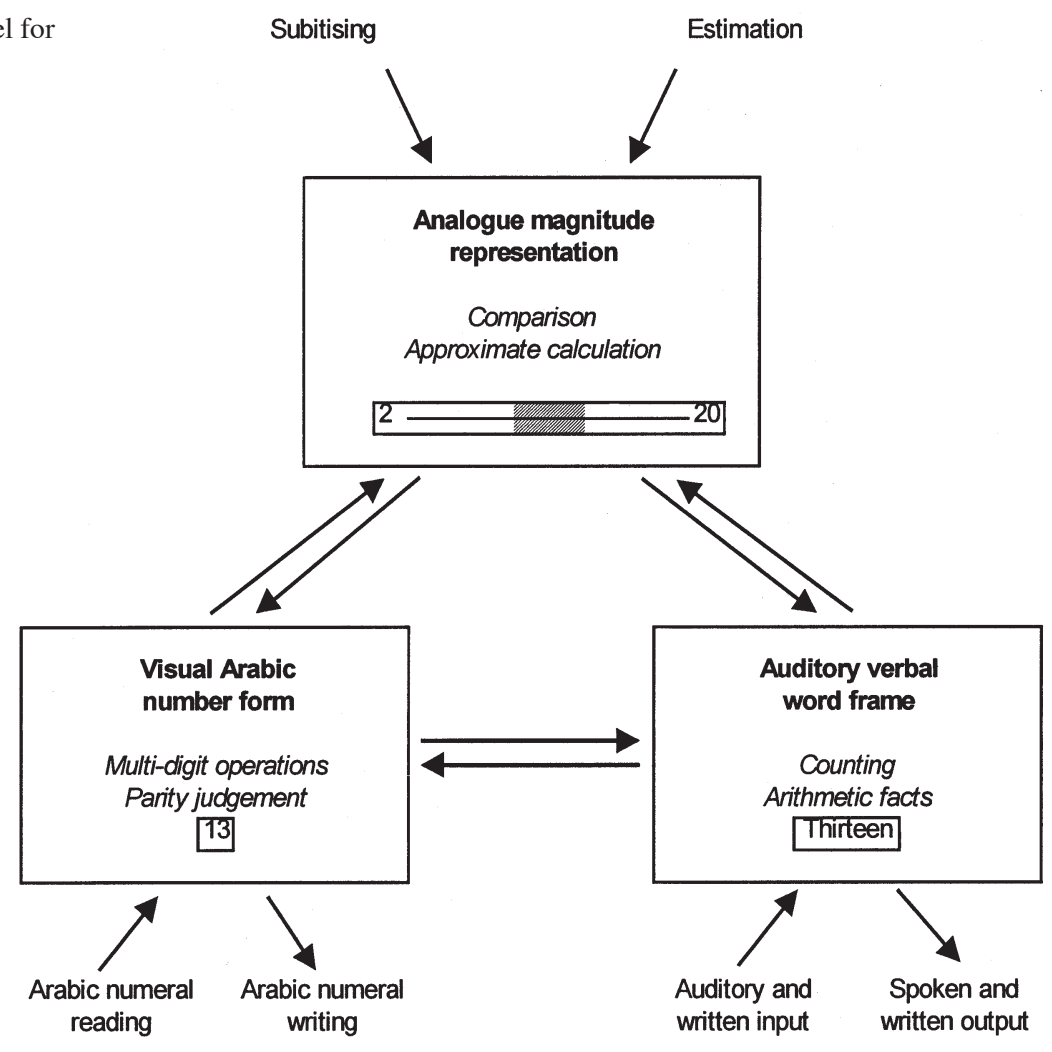

showed severe difficulties in retrieving arithmetic facts from memory ('number-fact dyscalculia') or in using arithmetical procedures despite a good understanding of the concepts of the arithmetical operations ('developmental procedural dyscalculia') have been stated to confirm certain elements of the model of McCloskey and coworkers (Fig. 2), in particular the existence of modules for number-fact and procedural knowledge (66).

Fig. 2 Model of the number processing system (43).

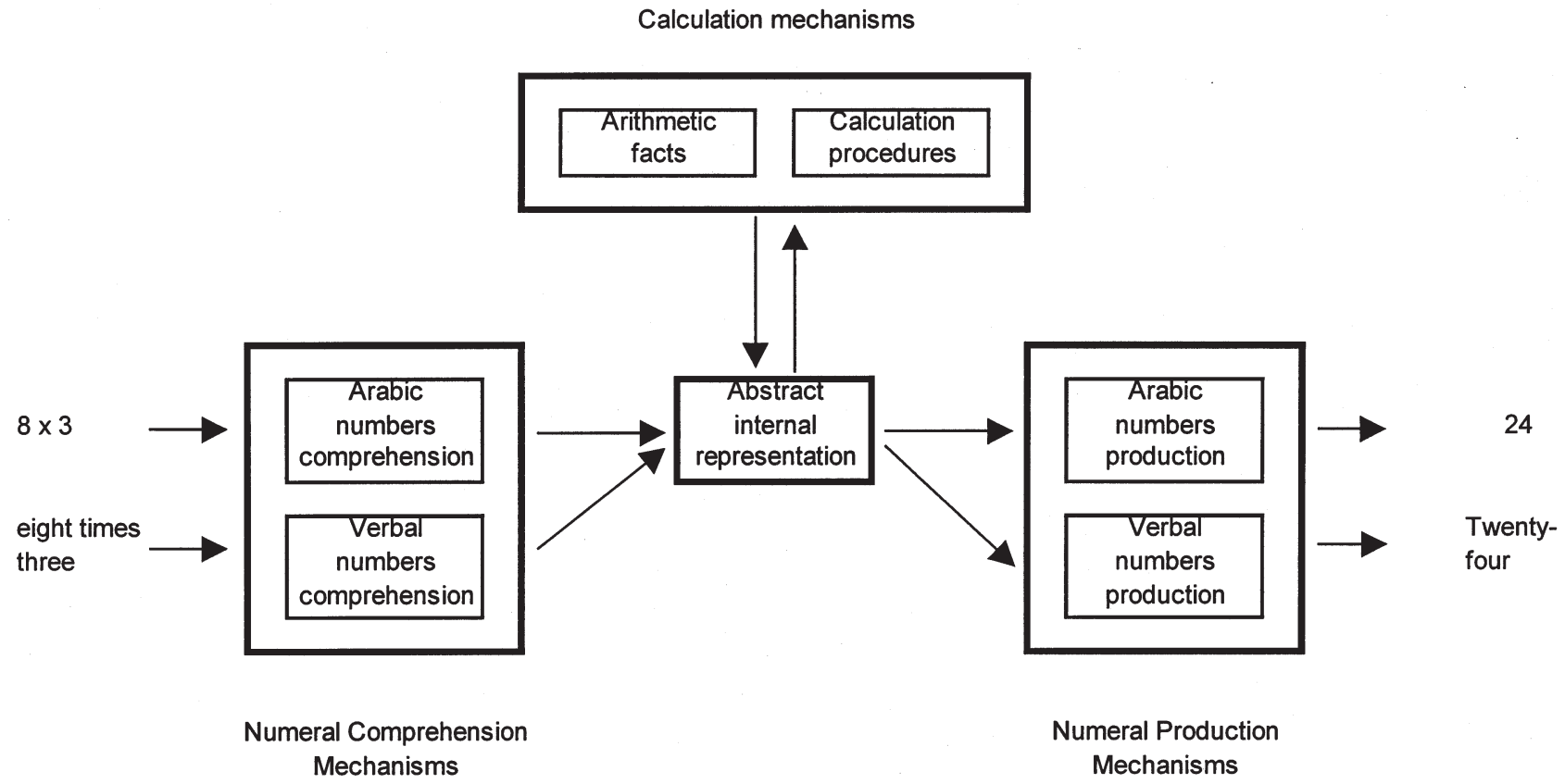


Different subtypes of DD have also been related to either left-hemisphere or right-hemisphere dysfunction according to characteristic deficits in arithmetical abilities and underlying deficits in phonological or visuo-spatial processing.

Geary (24), for example, related two DD subtypes to dysfunctions of the left hemisphere: a 'memory subtype' with a low frequency of arithmetical fact retrieval, often associated with reading difficulties, and a 'procedural subtype' with frequent use of developmentally immature procedures and a delay in understanding underlying concepts. Right-hemisphere dysfunction is, according to Geary, related to the 'visuo-spatial subtype', associated with a high frequency of errors that indicate misinterpretations of spatially represented numerical information such as place value.

Rourke and colleagues $(8,47,53,55,64)$ defined subtypes of learning disorders in children on the basis of patterns of scholastic strengths and weaknesses. They designated two subtypes of mathematically related deficits.

'Subtype RS' comprises children who manifest poor performance in mathematics and even poorer performance in reading and spelling. Subtype A, also called the "nonverbal learning disability' (NLD), comprises children who perform poorly in mathematics but perform adequately for their chronological age in reading and spelling. Both groups manifested characteristic discrepancies between verbal IQ and performance IQ. RS children showed higher performance IQs than verbal IQs, whereas the exact opposite pattern was found for the NLD children.

Evaluation of neuropsychological functioning has revealed children in the NLD group to have deficits in visual-spatial and tactile-kinesthetic perception as well as psychomotor deficits. These children make calculation errors more frequently and their errors are more diverse than those of children in the RS group. In the opinion of the authors, this indicates a lack of understanding of mathematical algorithms due to a disturbance in the process of non-verbal concept formation. The acoustic perception and memory, as well as the verbal skills of these children are developmentally age-appropriate.

The authors found the exact opposite neuropsychological pattern of strengths and weaknesses in RS children: good performance in visual-spatial and tactile-kinesthetic perception and deficits in acoustic perception and memory as well as verbal processing.

Rourke and coworkers attributed the deficits of the children in the RS group to functional disorders of the left hemisphere, and those of the children in the NLD group to disorders of the right cerebral hemisphere. A study by Mattson et al. (42) supports the hypothesis of complementary lateralized dysfunctions underlying the different subtypes of arithmetical disorders in childhood. The authors investigated the electroencephalograph activity $(36-44 \mathrm{~Hz})$ in children with dyslexia, children with arithmetical disorders and in control subjects while they were engaged in solving verbal and non- verbal cognitive tasks. The children with weaknesses in reading skills manifested less left-hemisphere activity while performing verbal tasks than either the children with a weakness in arithmetic or the control group. In contrast, while performing non-verbal tasks, the children with a weakness in arithmetic manifested less right-hemisphere activity than either the children with weaknesses in reading skills or the control children.

In an overview of his research findings, Rourke (52) ascertained a correspondence between the pattern of neuropsychological deficits in NLD and that described for the so-called 'developmental Gerstmann syndrome'.

The Gerstmann syndrome, described for the first time in 1930 by Gerstmann, comprises four symptoms that have been observed in adult patients with circumscribed left-hemispheric brain lesions in the area of the gyrus angularis: acalculia, finger agnosia, right/left disorientation and dysgraphia. The observation of these four symptoms in children without any verifiable previous brain damage prompted Kinsbourne (37) to propose a 'developmental Gerstmann syndrome' (DGS). The clinical validity of this syndrome has been critically discussed, especially considering the fact that the functional disorders referred to can, to a large extent, be explained by the concurrent aphasic symptoms that often occur (49). A series of investigations and clinical case studies $(6,27,46,48,58,61,62,69)$ contributes to the recognition that DGS is observed in children with DD, both with and without concurrent disorders in the areas of language and written language, as well as in combination with other neuropsychiatric symptoms. It is, therefore, impossible to singularly relegate DGS to a specific, localized functional brain disorder (7). Should one follow the concept of complementary lateralized functional brain disorders for the various subtypes of arithmetical disorders, it seems logical to postulate a disorder of right hemisphere function for the nonaphasic or non-dyslectic form of DGS and a disorder of left hemisphere function for Gerstmann symptoms with associated disorders in language processing.

The problem with those concepts which focus on basic dysfunctional processes of either the left or the right hemisphere are mainly that the presence of non-verbal or verbal neuropsychological deficits are not likely to predict DD precisely enough. Share et al. (60) were generally able to replicate Rourke's findings. However, in contrast to Rourke and coworkers, they considered gender differences in their data analysis and found that girls with a 'specific arithmetical disorder' do not manifest the expected NLD pattern of visual-spatial weaknesses, nor did their neuropsychological pattern of functioning differ from that of a control group. In our own study (70), only $50 \%$ of the children who fulfilled the criteria for DD showed a neuropsychological pattern that was characteristic for NLD. In contrast, there were children who indeed showed a typical NLD pattern of neuropsychological functioning but, nevertheless, perform well in mathematics $(28,39)$. 
Fig. 3 Theory of minimal cognitive architecture (1).

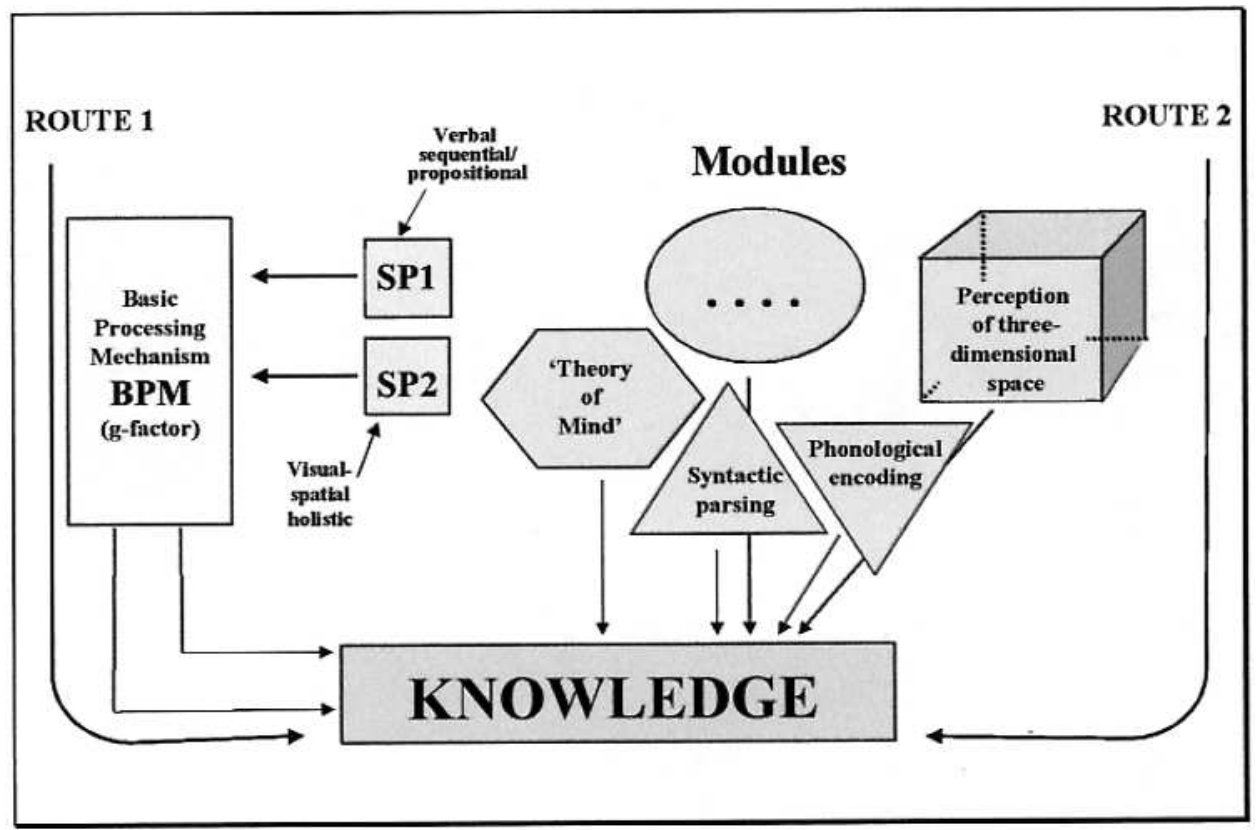

The still somewhat confusing evidence concerning different kinds of difficulties in numerical processing and cerebral functioning might find a clearer conceptualization within Anderson's theory (1) of the 'minimal cognitive architecture'.

Theory of the minimal cognitive architecture

Anderson's theory, which aims to account for the various individual differences in intellectual functioning, postulates two main developmental routes for the acquisition knowledge with three processing mechanisms being involved in these processes (Fig. 3).

Through route 1 , knowledge arises by thinking, generated by a 'basic processing mechanism' and two 'specific processors' (SP1 and SP2) that are characterized as knowledge acquisition mechanisms utilizing two different modes of processing; SP1 suited to verbal (sequential/propositional) and SP2 suited to spatial (simultaneous/holistic) material. With reference to cerebral lateralization of cognitive functions, SP1 can be viewed as a left-hemisphere processor and SP2 as a righthemisphere processor. Concerning route 1 , individual differences are explained by differences in the capacity of the 'basic processing mechanism' (expressed by general IQ); the faster knowledge is acquired, the more established during a period of time.

Possible differences in the latent power of the two specific processors are psychometrically expressed by differences between verbal IQ and performance IQ, but only in individuals with normal or high processing speed, since the speed of the basic processing mechanism constrains the complexity of specific routines that can be implemented.

Through route 2 , knowledge is not provided by thinking but quickly and automatically via 'modules' that mature at different times during development. Their computations are unconstrained by the speed of the basic processing mechanism. Modular processing is specified by Anderson for cognitive functions such as perception of the three-dimensional space, theory of mind, syntactic parsing and phonological encoding, some of these being evolutionary preformed and genetically transmitted (i.e. perception of the three-dimensional space), others with an ontogenetic rather than a phylogenetic basis, established through extensive practice and automatization during development. A recent example of the latter function may be seen in the development of a separate cortical representation for a second language within the Broca's area that has been documented in late bilingual subjects (36).

Anderson argued, for example, that the exceptional skills possessed by subjects with otherwise very low psychometric intelligence (savants) can be explained by the existence of modules that are functionally independent from the basic processing mechanism. Furthermore, his theory accounts for different types of reading failure: in children with a low general ability, a poor reading ability (as well as other scholastic skills) will be predicted by a low IQ. Therefore, reading failure (and poor scholastic achievement) is caused by a slow basic processing mechanism. Reading failure may also be caused by a poor specific processor (SP1) being manifested psychometrically by a correlation between reading problems and a discrepancy between low verbal IQ and high performance IQ, as 
also described by Rourke (51) for subtype RS. However, in children with an average IQ and no such discrepancy between verbal and performance IQ, dyslexia also occurs and, therefore, may be caused by a defective module for phonological encoding.

As for reading failure, it seems attractive to also conceptualize different kinds of learning problems in the areas of arithmetic and mathematics within Anderson's framework: NLD may, therefore, correspond to a poor specific processor for visual-spatial material (SP2), whereas children who have average intelligence without a pattern characteristic of NLD and who, nevertheless, have particular problems in manipulating numbers and performing calculations, may suffer from defective modularization of number processing and calculation abilities.

\section{Section 2: Subtypes of developmental dyscalculia: results from a Zurich study}

The complexity of the modular organization of the cognitive number processing and calculation systems, as pictured in the neuropsychological theory, makes it necessary to assess different aspects of the numerical domain separately in order to obtain a differential diagnosis that may be useful for planning appropriate intervention strategies. Within a European research network, the Neuropsychological Test Battery for Number Processing and Calculation in Children (NUCALC, $72 ; 17)$ has been developed. A similar version of this battery (EC $301 ;(18)$ ) has previously been developed within the same European research network for application to adult patients with acalculia.

The NUCALC battery contains 12 subtests investigating the following abilities.

\section{Counting}

Counting abilities are considered to be important prerequisites in children for the acquisition of addition and subtraction skills. In a first subtest, children have to enumerate different sets of dots. With reference to the theoretical framework elaborated by Gelman and Gallistel (26), four different basic abilities were evaluated and scored: (i) production of the conventional sequence of spoken verbal numbers, (ii) synchronization between manual pointing and oral counting, (iii) the visual memory dimension of the task with discrimination between the dots counted and those remaining to be counted, and (iv) transcoding the last spoken verbal number to its corresponding Arabic digit form (cardinality principle).

The second subtest is 'counting backwards'. This ability is considered important for the acquisition of counting-down strategies in subtraction (23). Whereas forward counting is the prototype of automatic cognitive processes, the production of the backward sequence of number-words is controlled by the working memory system.

\section{Number transcoding}

The subtests 'reading Arabic numbers aloud' and 'writing dictated Arabic numbers' represent the most common transcoding processes in early school age. Both tasks operate on the same numerical systems (Arabic digits and spoken verbal numbers) but exchange their source and object codes. The six items of each subtest have been constructed with reference to corresponding difficulty factors and verbal syntactical structures. Several dissociations in transcoding responses observed mainly in adult brain-damaged patients provided the empirical basis for different representational modules outlined in the previously mentioned models of number processing and calculation.

\section{Magnitude comparison}

Two subtests investigate the capacities of subjects to compare the arithmetical values of two numbers. The numbers have to be encoded correctly according to their lexical-syntactical structure (linguistic and Arabic) and they have to be assessed with respect to their internal magnitude representation. Different aspects of difficulties are systematically implemented both concerning the semantic representation (small and large distances) and notational aspects (length of number-words or digit strings). Impaired performances have been reported in group- and single-case studies of adult brain-damaged patients with aphasia as well as with right-sided lesions (10).

Mental calculation

Six problems for addition and subtraction are presented orally investigating simple number fact and procedural knowledge (i.e. 'five plus eight' or 'fourteen minus six'). In a second subtest ('story problems'), children have to solve addition and subtraction problems embedded in a situational context. These four tasks vary according to the level of difficulty and the type of problem (change, combine and compare; see 11).

\section{Placing Arabic numbers on an analogue number line}

This subtest, which includes five items, aims at evaluating the comprehension of numbers and capacities of subjects for numerical estimation, with reference to the analogue magni- 
tude representation system of the triple-code model postulated by Dehaene (12).

Perceptual quantity estimation

Children have to estimate the numerosity of two visually presented sets of objects (balls and cups).

\section{Contextual estimation}

The semantic values of numbers depends not only on their arithmetical value but also on the particular context. Children have to judge if, for example, 'ten leaves on a tree' or 'eight lamps in a room' are few, average or a lot. Recently, KoperaFrye et al. (40) reported that such cognitive estimation tests were the best indicators for calculation and number-processing impairments in patients with fetal alcohol syndrome.

A functional analysis of the NUCALC subtests with reference to the different representational modules and the specific input and output formats as well as the internal translation pathways mentioned in the triple-code model is presented in Table 1.

Normative data have been collected in a representative sample of $\mathrm{N}=279$ second- to fourth-grade children from regular schools in the canton of Zurich (72). Data from children of the same school grades have also been collected in France, Argentina, Brazil and Greece applying a French, Spanish, Portuguese and Greek version of the battery. Results of cross-cultural comparison studies have recently been published (14, 73).

Significant effects on the general test performance in the Swiss-German as well as in other populations have been found for age and grade level and also, as could be expected on the basis of the literature, for gender, favoring boys (especially in subtraction, verbal comparison and story-problem tasks).

In addition, in the Zurich population, foreign native language affected general test performance: surprisingly, this linguistic effect was only observed for the Zurich population. In contrast, in a French population, children with a native language other than French were not at a disadvantage in comparison to their native French-speaking classmates. An explanation may be that the confusing irregularities of the German number-word lexicon with the inversion of tens and ones ['23' - 'drei und zwanzig' (literally translated: 'three and twenty')] will disturb the acquisition of early transcoding routines. Bilingual or foreign-language children in German-speaking countries have to transcode number words from both the native language and the irregular second language (German) into the Arabic notational system and vice versa.

The validity of the instrument has been investigated concerning the external criterion of school failure in mathematics. The NUCALC clearly distinguished children who were indi-

Table 1 Functional analysis of the NUCALC subtests with reference to the triple-code model (12).

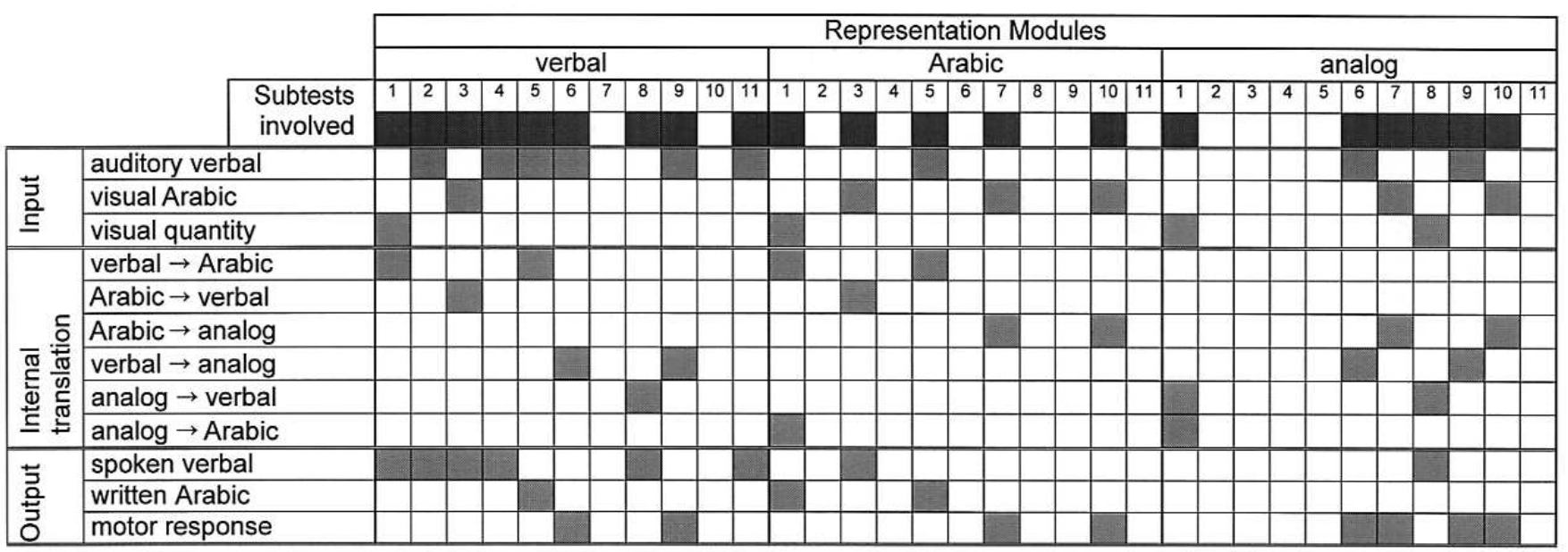

Subtests

1 Enumeration

2 Counting backwards

3 Reading Arabic numbers aloud

4 Mental calculation (+/ -)

5 Writing Arabic numbers from dictation
6 Magnitude comparison of spoken numbers

7 Placing numbers on an analogue number line

8 Perceptual quantity estimation

9 Contextual magnitude judgement

10 Magnitude comparison of Arabic numbers

11 Story problems 
cated by their teachers to have significant problems in coping with school mathematics from those children who had no learning problems according to teacher ratings. The internal consistency for all 63 test items of the battery expressed by Cronbach's alpha coefficient was .92.

\section{Subjects}

The test results of 93 children with poor achievement in school mathematics, chosen partly from a normal school population (identified by school performance measures and teacher ratings) and partly from a child psychiatric referral population (identified by ICD-10 criteria), have been used to investigate subgroups of children with different patterns of disablement. The mean age of the children included in this study was 9 years 11 month, ranging from 8 to 10 years 11 month. The children from the clinical sample were all attending regular school curriculum and were of normal intelligence. The ratio of the two sexes was 52 boys/41 girls. However, in the sub-population extracted from the normal school population, there was a slight over-representation of girls (52.5\%) whereas, in the clinical sub-population, girls have been underrepresented (29.4\%), which reflects the general distribution of the sexes in clinical

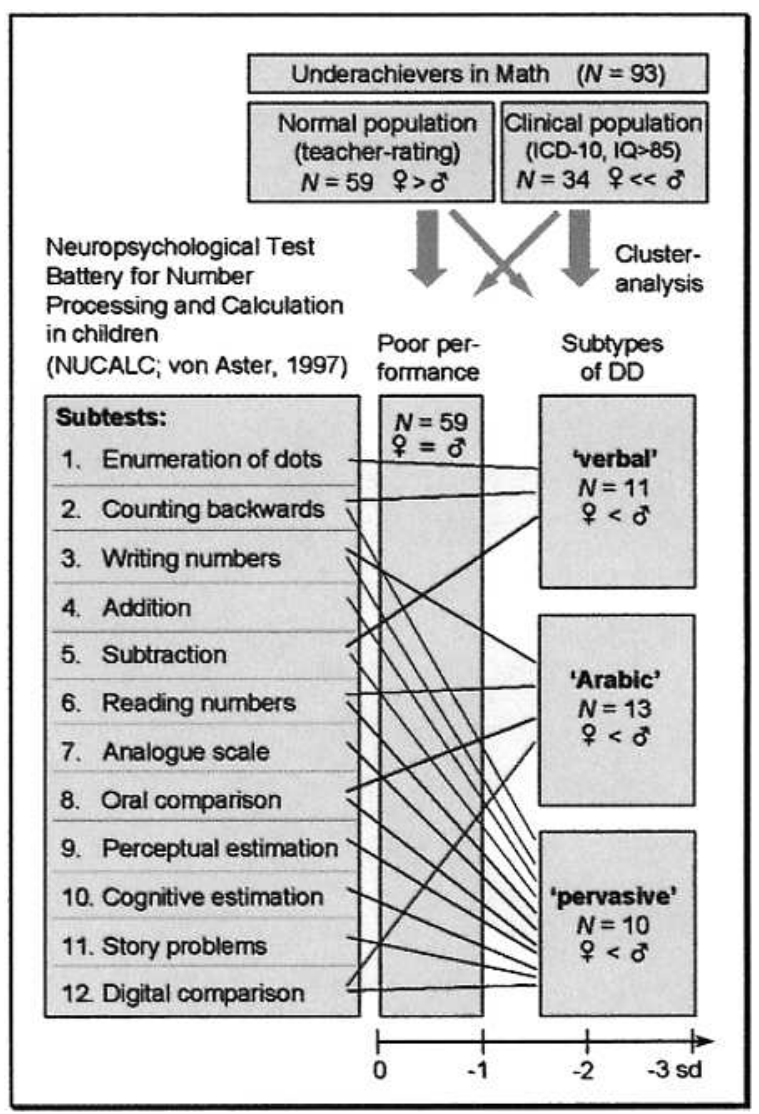

Fig. 4 Subtypes of developmental dyscalculia. child psychiatric referral as well as special-educational populations.

Methods

For statistical analysis the test results were corrected for age and according to the different lengths of the subscales, the rawscores were transformed to z-values. Cluster analysis (SPSS 6.0) was used to classify subjects according to similarities in performance patterns.

\section{Results}

Applying the NUCALC test profile, a four-cluster solution was identified, comprising three groups of children who showed a mean sum score in more that one subtest greater than 1.5 standard deviations below that of the normal school population and one larger group of children with a mean total score significantly lower than that of the normal population, but not more than one standard deviation in each subtest (Fig. 4).

The latter group has been defined as being a 'sub-clinical' group of poor performers whereas the former three groups have been defined as representing clinical subtypes of DD.

Some $(\mathrm{N}=13)$ children from the clinical sub-population were classified into the poor-performance cluster, indicating a false-positive diagnosis according to ICD-10 criteria on the basis of NUCALC test results. In contrast, 13 children from the non-clinical sub-population were classified into one of the three clusters with DD.

With reference to the representative sample of normal school children, the prevalence of children with one of the three subtypes of DD has been estimated to be $4.7 \%$, which corresponds with findings from other recent studies $(29,38)$. The number of children to be classified as poor performers has been estimated as being $16.5 \%$. More boys than girls were in the three clinical subtype groups and a ratio of 1:1 in the poorperformance cluster.

The three subtypes of developmental dyscalculia

The first subtype was labeled 'verbal subtype'. Children who clustered into this group had greatest difficulty with counting routines. Consequently, they failed to use counting procedures to perform mental calculations correctly, especially for subtraction and also to store arithmetical facts. Most of these children ( 9 out of 11) had additional difficulties in reading and spelling and about $50 \%$ of these children (6 out of 11 ) also had attention deficit hyperactivity disorder (ADHD).

The second subtype was labeled 'Arabic subtype'. Children who clustered into this group showed severe difficulties in 
reading Arabic numbers aloud and in writing Arabic numbers to dictation. It seems likely that the difficulties observed in the number-comparison subtests (especially when items were presented digitally) are conditioned by these transcoding problems, considering that relating numbers to analogue positions on a scale and estimating quantities is not a problem for these children. Most of the children who clustered in this subtype only had learning problems in the area of mathematics. However, for more than $50 \%$ of these children, German was a second language.

The third cluster has been labeled 'pervasive subtype'. Children who were classified into this group had severe problems in almost all subtests. Nearly all of these children (9 out of 10) also had reading and spelling difficulties, and the majority (7 out of 10) manifested behavioral and emotional problems of clinical significance and, in some cases, also ADHD.

\section{Discussion}

The results must be taken very preliminary due to the limited sample size. However, as insinuated before, it could be suggested that, concerning the three modules defined within the framework of the triple-code model, different maturational dysfunctions are involved in the three subtypes, arising at different stages of development.

Children showing the pervasive subtype pattern may suffer from defective maturation of an analogue magnitude module, probably caused by genetic influences or early brain damage. According to Dehaene et al. (13), the analogue module that is supposed to be inborn represents the basic 'sense' of numerosity and encodes the semantics of numbers. This module develops and elaborates from the preverbal numerical abilities (that have shown to be present in infants) to an expanding visualized inner number line throughout childhood. It could be speculated that a malfunction of this genetically preformed module will impede the development of later mathematical abilities, in particular the maturation of the verbal and Arabic representational modules and the associated acquisition of number fact and procedural knowledge. The difficulties children experience in filling number symbols (words and digits) with a proper corresponding visualizable number meaning may represent the causal mechanism that leads to inabilities, not only to approximate and estimate numerical relationships but also to store number facts and tables and to perform arithmetic procedures.

Children showing the verbal and the Arabic subtype pattern did not have difficulties that can be understood as a defective basic 'sense' for numbers and numerosity. They are able to perceive and to compare quantities, to make judgements concerning approximate values and to build up an inner analogue number line. Children with these kinds of difficulties have particular problems in learning, processing and transcoding two culturally transmitted systems of number symbolization, (verbal/alphabetical and Arabic), each with characteristic lexicons, syntax rules and designations for different utilizations.

Children classified into the verbal subtype failed to count accurately and correctly. Even if they mastered the counting word sequence, they made frequently errors in enumerating sets of objects properly by missing one, taking one twice or violating the one-to-one correspondence. During the development of counting strategies for solving simple addition and subtraction tasks, these children may have miscounted frequently (i.e. solving the problem $3+5$, they do not always reach 8 but frequently also 7 or 9). As a consequence, retrieval strategies and number-fact knowledge could not be established appropriately and the children rely on time-consuming, vulnerable and immature counting strategies. In our sample, 6 out of 11 children showed ADHD and had an impulsive and hasty working style which might have contributed to faulty counting. According to our clinical experience, these children will have a relatively good prognosis if the ADHD is treated early and successfully, and no other comorbidity is present. However, reading and spelling difficulties as well as developmental disorders of speech and language are also relatively common in this group of children. Depending on the type and the severity of such associated disorders, the development of elaborated analogue representations may also be constrained as described in the next section.

Children with the verbal subtype generally do not have difficulties in acquiring the Arabic notational system and in transcoding Arabic digits to verbal numbers and vice versa, as do children classified in the Arabic subtype cluster. Most of the errors that characterize the performance of these children occur in reading Arabic numerals, writing Arabic numerals to dictation as well as in cognitive number comparison tasks, especially when the pairs of numbers are presented digitally.

Compared to the normal population, children with a mother tongue other than German were overrepresented in this group. Upon school entrance and systematic instruction of the Arabic notational system, these children have to apply multiple rules and routines for number transcoding between the native and the second-language number-word sequence and between both and the Arabic notation system. This may constitute a substantial risk for the maturation of the Arabic module and for the acquisition of arithmetical procedures that depend on this particular Arabic representation (written multi-digit calculation). However, this kind of learning difficulty may vary with the presence of more or less sophisticated irregularities in the number-word lexicons of the spoken languages, with the time at which a child is first exposed to a second language and the intensity of exposure. It would be quite interesting to investigate whether this phenomenon is specific for certain characteristics of number-word lexicons and, therefore, is possibly restricted to specific language areas (i.e. German). The crosscultural differences in mathematical performance between 
East-Asian children and children from European countries and the U.S. have been considered to be partly due to linguistic factors that favor East-Asian children, since East-Asian number-word lexicons correspond quite closely to the Arabic notation system $(44,45)$. Another characteristic feature of the Arabic number symbolization is its purely visual-spatial representation, though children with visual-spatial processing deficits (such as left-right disorientation) may also experience difficulties, for instance with the place value system and vertical alignments.

\section{Section 3: Course and outcome of DD in a 17-year-old boy}

\section{Referral}

$\mathrm{HN}$ was referred by his mother due to increasing symptoms of depression and suicidal thoughts, social anxiety, isolation and refusal to attend school. He had a long history of learning disabilities which were most pronounced in the areas of mathematics but also affected reading and spelling. $\mathrm{HN}$ is presently in the 10th school year (Werkjahr) that prepares for a vocational apprenticeship.

\section{History}

HN's parents divorced when he was 1.5 years old. Both parents have an academic background; the father had mild dyslexia during his early school years. The mother's older brother had problems with mathematics during primary school education. There is no other family history of mental diseases or academic failure.

According to the mother's report, pregnancy, birth and primary adaptation were without problem, $\mathrm{HN}$ was a quiet infant with slightly delayed motor milestones. At the age of 2.5 years, he attended a toddler group where his mother noticed that he had a retarded language development compared to other children of the same chronological age. At the age of 4 years, he attended preschool; for the first few weeks, HN experienced severe separation anxiety and his mother had to stay with him. One year later, the mother was reported that her son was rather hyperactive, inattentive, frequently experienced fits of rage and destroyed play material.

When HN was 6 years old, the mother moved with her son from Germany to Switzerland but HN never adapted to the Swiss-German dialect. A first child psychiatric consultation diagnosed a developmental delay and, as HN was of normal intelligence, a special educational setting within a regular school curriculum was proposed.
At the age of 7 years, $\mathrm{HN}$ attended a private school with a small class size and a regular curriculum. According to a second neuropediatric and child psychiatric examination, minimal brain dysfunction with deficits in attention, motor control and perception as well as a hyperkinetic disorder was diagnosed and HN was attended psychotherapy, psychomotor and sensory-integration training. A year later, he was moved to a regular primary school, staying there for two years, manifesting increasing learning problems. At the end of the second grade, an extensive psychological assessment diagnosed a developmental language disorder, a developmental disorder of motor function, a combined disorder of scholastic skills (dyslexia and dyscalculia) and an attention-deficit hyperactivity disorder. The following results were obtained: normal intelligence with a discrepancy between low verbal and average performance (IQ); poor measures of phonological segmentation and verbal memory span; average measures concerning visual-motor coordination and visual-spatial processing. Results of an electroencephalography showed no dysfunctionality.

Acting on professional advice, $\mathrm{HN}$ was transferred to a school specialized for children with developmental language disorders. Here he received special training in reading and spelling as well as in arithmetic.

In spite of these various therapies, HN's academic performance did not improve satisfactory. At the age of 11 years, after repeating the third grade, he was reported to be non-motivated, unhappy and to have a very low self-esteem. He told his mother that he was afraid of other children, that he did not like school and he began to refuse to attend school. A phoniatric examination came to the following 5 diagnoses: dysnomia, dysfluencia, dyslexia, dyscalculia, dysgraphia.

Due to repeatedly refusing to attend school, $\mathrm{HN}$ was transferred to a boarding school where reading, spelling and mathematical training as well as speech therapy and psychotherapy were continued.

At the age of 15 years, he refused to return to the boarding school after a summer holiday spent with his mother. He lived with his mother for the next two years and attended the 7th and 8th grades at a special school for handicapped children. During that period, he again refused to go to school over several weeks, reported that he was afraid of other children, became more and more isolated and failed to make friends. His mother noted increasing depressed moods and withdrawal.

\section{Psychiatric examination}

$\mathrm{HN}$ is a good-looking, fashionably dressed adolescent who is able to establish contact in a friendly and polite manner but seems slightly embarrassed and shy. He is left handed. His difficulties in comprehending complex and longer sentences within verbal communication were not immediately clear due 
to his well developed abilities to express non-verbally through gesture and mimic full awareness of what had been said and to mask incomplete comprehension. His verbal comprehension and reciprocal communication improved markedly if conversation was slow and used short sentence constructs. His own verbal expression seemed sufficient for social pragmatic belongings, not dysgrammatical, but simple concerning syntactical structure and vocabulary. $\mathrm{HN}$ is painfully aware of his learning difficulties and he considers himself to be stupid. He is afraid of other adolescents, has long experiences of being teased and he is convinced that he is completely unattractive to other peers. During the last year, he often thought about killing himself but had not followed through his thoughts in light of the effect that his suicide would have on his mother. No symptoms of attention deficit or hyperactivity could be registered, even during psychological testing.

In summary, $\mathrm{HN}$ is a 17-year-old adolescent of low average general intelligence with a long history of learning problems and school failure who has received various forms of treatment and repeated psychological, medical and special educational work-ups over a number of years. He has a low self-esteem, negative self-attitudes, a social phobia and is actually depressed. He has developed much better reading than spelling skills, the most inferior area of school performance being mathematics.

Investigation of number processing and calculation abilities

HN was administered the EC 301-R (18). This test battery contains 13 subtests that investigate different abilities: counting, number transcoding (spoken, written verbal and Arabic format), mental and written calculation, approximate calculation and story problems, magnitude comparisons on spoken, written verbal and Arabic numbers, contextual magnitude estimation, perceptual quantity estimation and placing Arabic and spoken numbers on an analogue number line. In addition, EC 301-R containes subtests that investigate knowledge concerning arithmetic signs and numerical facts of everyday life.

\section{Results}

Except for minor difficulties in counting backwards, HN had no problems with counting and enumerating different sets of dots and he also responded correctly to questions concerning numerical facts of everyday life (i.e. how many days are in a week? how many minutes are in 1 hour?).

HN had severe difficulties in transcoding written verbal or orally presented numbers into their Arabic notation, especially when the number-words comprised more than two elements. (i.e. spoken verbal: 'eleven-thousand-six-hundred-and-thirty' $\rightarrow$ '110630', 'one-hundred-and-eighteen' $\rightarrow$ '818'; written

\section{2 wölftausen vierhurderfinflyg

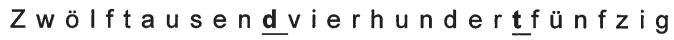 \\ Twelve-thousand-four-hundred-and-fifty}

Fig. 5 Transcoding from Arabic to the written verbal code by HN.

verbal: 'five-hundred-thousand' $\rightarrow$ '5000', 'three-hundredand-eighty-seven' $\rightarrow$ '30078'). The rate of errors was $55 \%$ (near-chance performance). In contrast, he was much better in transcoding in the reverse direction: Arabic numbers into verbal or written verbal numbers (15\% incorrect responses). However, his handwriting was rather disorganized and he made lots of spelling errors (Fig. 5).

This pattern of verbal/Arabic dissociation also appeared when $\mathrm{HN}$ was asked to compare two numbers according to their magnitude. He was faultless when the numbers were presented in Arabic notation but had great difficulty with the corresponding orally presented comparison tasks, where he failed in $50 \%$ of the items. The type of errors indicate that his false decisions were related to the length of the number words and to the values of the ending elements (i.e. 'one-hundred-thousand-and-sixty-five' was indicated to be more than 'three-hundred-thousand' and 'seven-hundred-and sixty-nine' was more than 'two-thousand-and-thirty-five').

The pattern of transcoding problems indicate that $\mathrm{HN}$ had markedly impaired verbal number comprehension mechanisms, much better verbal number production abilities and a nearly preserved ability to process Arabic numerals. He could comprehend and produce arithmetical signs without problem and he was also able to arrange written calculations correctly (addition and subtraction) according to their vertical alignments. He could solve written multidigit addition and subtraction tasks without problem but he failed to solve written multiplications correctly, due to left-right confusion in the vertical arrangement of the indented intermediate results from which each one was calculated correctly (Fig. 6).

On simple exact mental calculation problems (addition, subtraction, multiplication and division, presented orally as well as digitally, all with values smaller than 50), HN responded to $87.5 \%$ of the items correctly. Errors only occurred in mental subtraction (i.e. ' $14-6$ ' = 4). However, he was unable to correctly solve simple arithmetical problems that were embedded in an orally presented situational context (story problems).

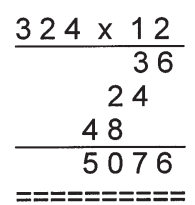

Fig. 6 Multiplication as written by HN. 
HN responded correctly to only $25 \%$ of the items that investigated approximate calculation (problems were presented in Arabic format, i.e. ' 1520 - $780=2300$ or 1450 or 400 or 700 '). Correct answers were only registered in one addition and one subtraction problem, both items being composed of relatively small numbers with results smaller than 1000 . He failed to approximate addition and subtraction problems that contained operands larger than 1000; he failed completely to approximate multiplication and division problems.

In contrast, $\mathrm{HN}$ was faultless in perceptual quantity and contextual magnitude estimations (quantities always smaller than 100) and he could also relate Arabic as well as spoken numbers very well to analogue positions on a scale ranging from 0 to 100 .

\section{Discussion}

HN showed psychiatric symptoms that were reported to be most frequently associated to developmental dyscalculia: ADHD and internalizing disorders such as anxiety and depression $(54,59,71,72)$. However, while ADHD had decreased, the symptoms of anxiety and depression had increased during the course of HN's development. It can be speculated that attention deficit and poor phonological awareness might have hampered the modularization of verbal number processing mechanisms during the early school years. Consistent experiences of failure and of feeling different from other peers might have been followed by increasing symptoms of anxiety, depression, poor motivation and refusal to attend school which, in turn, might have contributed to poor learning progress.

An actual psychometric intelligence test was not done. The results of the previously mentioned tests correspond quite well to the pattern that has been described by Rourke (52) as characteristic of subtype 'RS' (see above). The difficulties HN experienced in left-right orientation along with his graphomotor problems indicate the presence of developmental Gerstmann syndrome (DGS) as well (however, finger agnosia was not evaluated). Subtype RS and DGS and also developmental language disorder and dyslexia have been considered to represent left-hemisphere dysfunctions. With reference to the mechanisms of Anderson's theory of minimal cognitive architecture (1), one could postulate that $\mathrm{HN}$ has a poor specific processor for verbal material (SP1). Whether or not a poor SP1 will impede the maturation of certain modules might be an interesting theoretical question concerning possible interactions between the different mechanisms that constitute the two routes of knowledge acquisition in Anderson's theory. With the assumption of format-specific representational modules for number processing, as proposed in the triple-code model by Dehaene (12), it can be supposed that the development of two modules has been disturbed in $\mathrm{HN}$ : the verbal module and the analogue magnitude module.
As pointed out in section 2, the analogue magnitude module provides an essential meaning, the semantics of numbers. This module has been supposed to rely on primary inborn and preverbal abilities of numerical quantification and is conceptualized as an inner number line that is variable and heteromorphic (16). According to HN's pattern of dysfunction, it can be argued that the mental construction of this (growing) number line depends on an appropriate mastery of verbal number symbolizations in order to label the tick marks that constitute the number line.

$\mathrm{HN}$ was not able to build up abstract analogue representations for very large quantities, due to limited abilities to represent larger numbers verbally and to assign appropriate names to larger quantities (verbal representation). He was still able to construct and enlarge an inner number line up to about 100, including all values he could symbolize verbally. However, his difficulties in comparing pairs of orally presented numbers and to approximate results of arithmetic operations composed of large numbers might indicate his inability to visualize and locate large numbers internally. A spoken number-word such as 'three-thousand-eight-hundred-and-thirty-seven' might be perceived by $\mathrm{HN}$ as a fuzzy convolute of names, each element sounding familiar, but too long to be fixed in his working memory, therefore being identified as a particular symbol for one single number such as 'three' or 'twenty-eight'. This, however, would appear to be a necessary condition to evaluate that 'three-thousand-eight-hundred-and-thirty-seven' is less than 'three-thousand-eight-hundred-and-thirty-nine', more than 'three-thousand-eight-hundred-and-thirty-four' and approximately half of 'eight-thousand'.

HN showed a classical pattern of verbal/Arabic dissociation (43). He was able to read Arabic numerals (Arabic encoding, internal translation and verbal production) and to compare pairs of Arabic numbers, even of larger size, correctly. It seems that he had learned the syntactic rules of the Arabic notation as well as the transcoding rules quite well. He was also able to carry out written multidigit calculations successfully, although he could not predict by estimation whether a result could logically be correct or not, presumably due to his limited abilities to locally visualize large numbers on an internal number line.

\section{Section 4: \\ A comprehensive model of developmental dyscalculia}

\section{Different subtypes}

The study presented in section 2 describes three different subtypes of DD in children with normal intelligence that have been interpreted to reflect impairments in the maturation of particular representational modules, as proposed in current 
Fig. 7 Theory of minimal cognitive architecture (1); adapted for disorders of number processing and calculation.

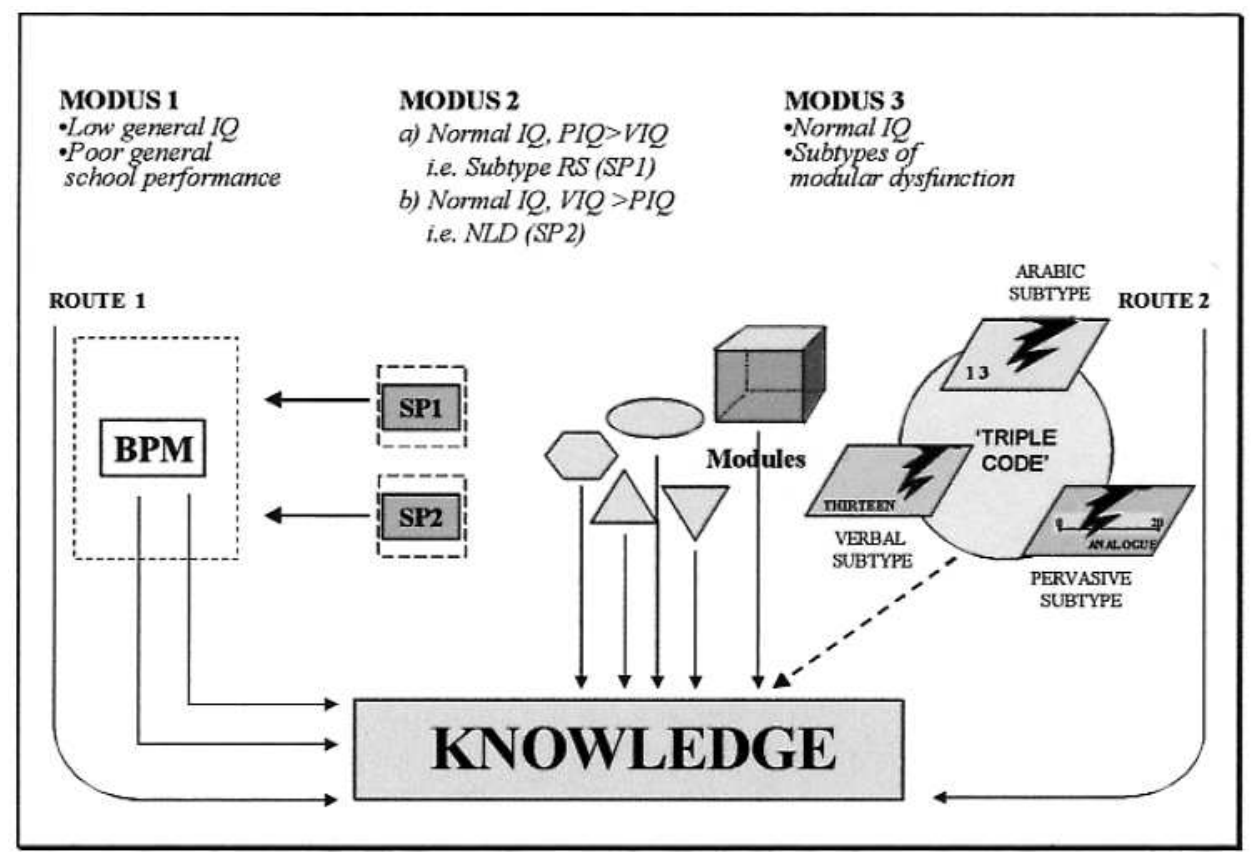

cognitive-neuropsychological models such as the triple-code model of Dehaene (12).

The verbal subtype represents a disorder of lexical/syntactical verbal representations of numbers, the use of languagebased arithmetical procedures (i.e. counting strategies) and arithmetic fact retrieval.

The Arabic subtype represents a disorder in the acquisition of the second 'number language', the Arabic notation system, including problems in reading, writing and comparing Arabic numerals, for instance by violating syntactic rules such as place value positions.

The pervasive subtype represents a lack of primary semantic concepts of number and numerosity, which implicates an inability to develop appropriate analogue number representations such as an internal number line. Secondly, it represents also an impaired development of verbal and Arabic representations and related computational skills.

We will now try to explain these findings as well as other mentioned concepts on DD within the theoretical framework of the minimal cognitive architecture' proposed by Anderson (1). Figure 7 illustrates the three subtypes at the level of modular dysfunction within route 2 of Anderson's theory (Modus 3).

With reference to Fodor (22) and Karmiloff-Smith (35), two different types of modules have been proposed by Anderson (1); the first, innate and given as a result of evolutionary pressure (labeled 'Mark I'), the other being acquired during individual development according to learning and automatization processes (labeled 'Mark II'). The analogue magnitude representation from Dehaene's triple-code model can be con- ceptualized as a Mark-I-type module, whereas the verbal and the Arabic number representations are more likely to represent modules of the Mark-II type. It can therefore be concluded that the pervasive subtype is likely to be caused by genetic ${ }^{1}$ influences or early brain damage, whereas the verbal and Arabic subtype are more likely to be caused by linguistic developmental disorders, probably due to genetic as well as environmental influences. Geary's (25) distinction between biological primary and secondary abilities describes the same condition from a cognitive-developmental perspective. Biological primary (universal) quantitative abilities in Geary's concept correspond to those mechanisms attributed to the analogue magnitude module in Dehaene's model, whereas biological secondary culturally transmitted abilities might correspond to verbal and Arabic representational modules.

NLD and subtype RS (see above) are the best known examples for concepts that postulate lateralized hemispheric dysfunction for DD which could be related to the specific processors (SP1/SP2) in Anderson's theory (Modus 2 in fig. 7). However, as reviewed in section 1 poor visual-spatial processing as well as poor language processing are not strongly predictive for developmental dyscalculia, but indeed these conditions constitute an increased risk. It seems plausible that a poor SP1 or SP2 might seriously interfere with the processes of

\footnotetext{
${ }^{1}$ In $42 \%$ of children with DD from an Israeli population-based study, a positive family history for learning disorders has been found, suggesting genetic influences (28).
} 
modularization: poor capacity to process particular qualities of information (verbal/propositional, visual-spatial/simultaneous) may restrict knowledge acquisition and result in poor automatization and modularization of certain abilities. This interaction might take place, for example, in children with developmental language disorders (poor SP1). It is well known that these children frequently exhibit phonological dyslexia, problems in mastering a second language or in number processing and school arithmetic, probably due to the limited maturation of linguistic modules. In contrast, children with NLD (poor SP2) might have a handicap for the modularization of particular cognitive abilities that rely on visual-spatial processing mechanisms and frequently result in school-related learning difficulties such as visual-spatial subtypes of dyslexia and developmental dyscalculia. Poor specific processors might also impede the modularization of other related cognitive functions. For example, NLD has been reported to be frequently associated not only with DD but also with disorders of empathy and social interaction (autistic spectrum) $(39,54)$. It can be speculated that non-verbal processing deficits that include poor face recognition may hamper the maturation of 'theory of mind' that is supposed to play a central role in the development of social competence and that have been supposed to be modularly organized in Anderson's theory (1).

Modus 1 in Fig. 7 finally represents poor mathematical abilities predicted by poor general intellectual capacities as expressed by a low IQ which corresponds to a poor basic processing mechanism in Anderson's theory.

\section{Developmental dynamics}

The three representational modules pictured in the triple-code model are supposed to be functionally autonomous, with specified input, output and transcoding mechanisms, and activated according to the demands of a certain problem. Taking this model as representing the end stage of adult number processing and calculation, it will now be argued that these modules emerge and elaborate at different stages in development. Furthermore, it will be argued that the development of the modules and neural networks depend (i) on certain genetic predispositions, (ii) on specific environmental influences and (iii) with regard to each individual module, on the developmental progress of the neighboring number modules.

The set of inborn, probably universal numerical abilities described by Starkey et al. (63) that constitutes the core of Dehaene's analogue semantic number representation seems necessary to understand how and why number-words are used and to grasp basic numerical principles (increase/decrease, part/whole), counting principles and arithmetical concepts. Without these semantic roots, number-words and arithmetic algorithms are learned by route and produced without really knowing what has been done and why. The pervasive subtype described in section 2 has therefore been postulated to be caused by genetic factors or early brain damage.

$\mathrm{HN}$ was able to understand and use basic number principles but had severe difficulties in learning number-words that were composed of more than two sequential elements. It seems that this was due to a severe, probably also genetically transmitted, language developmental disorder. It has been argued that the difficulties experienced by $\mathrm{HN}$ are due to a defective maturation of the module designated for verbal/alphabetical number representation. This might have been detrimental for further elaboration of analogue representations of larger numbers, which meant that $\mathrm{HN}$ failed to internally construct and represent numbers that he could not name appropriately. He could not build up an inner number line for larger numbers and, consequently, he could not process them mentally while calculating. HN could, however, produce larger number-words while reading Arabic numbers because he had mastered the Arabic
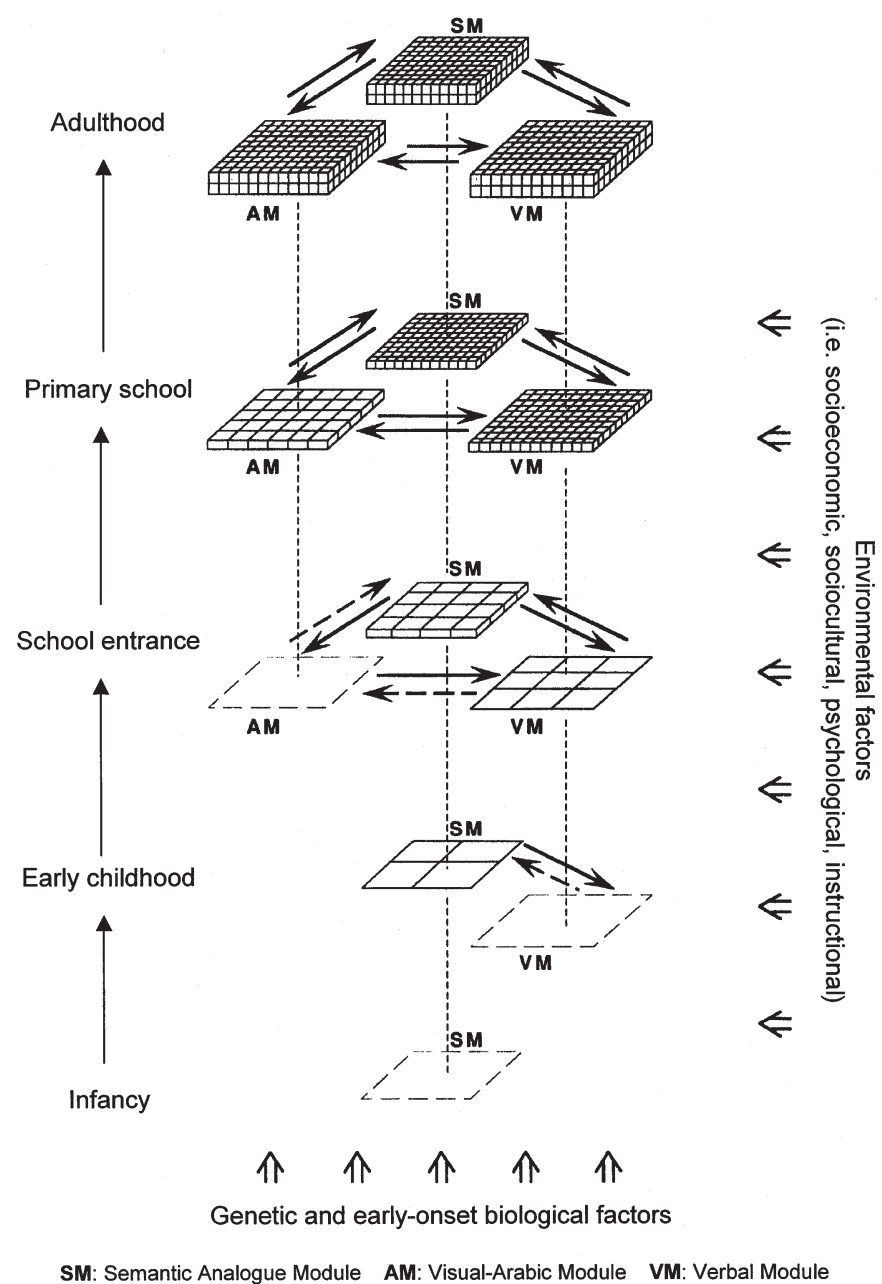

Fig. 8 Developmental dynamics of modularization of number processing and calculation abilities. 
notation principles well and was able to use the visually represented sequence of digits as an aid to articulate the corresponding number-word correctly but without being able to visualize the number analogically. Therefore, the elaboration of analogue representations seems to rely on appropriate linguistic representations. However, this elaboration may also be influenced by other environmental factors that could explain cross-cultural differences, i.e. differences between European and South-American children when instructed to place numbers on an analogue number line (14).

Finally, different linguistic factors that characterize number-word sequences in different languages might contribute to particular difficulties that are experienced by foreign-language or bilingual children in acquiring the Arabic notation system and written calculation procedures in the school environment (73). These children have to transcode from two number-word sequences which have different linguistic irregularities, i.e. German and French (or Spanish) into the Arabic notation. These linguistic confusions but also problems in left-right orientation and spatial processing might disturb the learning of particular symbols and syntactic rules of the Arabic notation and therefore impede the maturation of the Arabic module as supposed for children showing the Arabic subtype pattern (see section 2).

In conclusion, it seems that the arising and elaborating cognitive number representations are semi-autonomous during development, each depending on adequate developmental progress of the others.

Mediating and moderating environmental factors (right side in Fig. 8) has been found to contribute to individual differences in mathematical performance (for current overviews, see 24 and 19). Factors that have been of particular interest in the discussion of mathematical development and DD are those of gender $(24,70)$, interactions between learn- ing and psychological functioning $(3,32,71)$, influences of social class and cultural environment $(29,68)$, as well as aspects of formal education and instructional methods $(4,14$, $31,50)$.

Prevalence rates for DD have often been reported to be higher for girls than for boys, which seems to reflect a universal gender effect on the development of mathematical skills. The fact that the prominence of this effect is highly variable between different countries and that this effect has decreased over the last decades $(33,34)$ indicates that it is not likely to be explained only by the biology of the female (5). Several alternative hypotheses have been posed to explain the gender effect (30). Differences between boys and girls in attitudes, self-esteem (67), and specific anxiety (3) might play an important role in establishing motivated and self-directed learning. Educational settings and instructional methods might also subtly favor boys when they do not appropriately reflect differences in cognitive styles, algorithmic thinking and preferred learning environments between boys and girls $(56,57,75)$. In the Zurich study summarized previously, a higher rate for girls among poor-performing children from a normal population was also found. However, according to these results, boys are nevertheless over-represented in all three groups of children with subtypes of DD, a preliminary result which has to be confirmed by studies on larger samples.

In children with DD, behavioral and emotional symptoms as well as other learning difficulties frequently coexist, sometimes preceding, sometimes proceeding experiences of school failure, both of which were the case for HN. The quantity and severity of comorbid disorders has a strong prognostic value for overall personality adjustment and academic outcome (20, 21). Early diagnosis and early intervention, matched to differential assessment are urgently needed to prevent such negative vicious circles.

\section{References}

1. Anderson M (1992) Intelligence and Development. A Cognitive Theory. Oxford: Blackwell

2. American Psychiatric Association (1994). Diagnostic and Statistical manual of Mental Disorders ( $4^{\text {th }}$ edn) Washington, DC: APA

3. Ashcraft MH, Faust MW (1994) Mathematics anxiety and mental arithmetic performance: An exploratory investigation. Cognition and Emotion 8: 97-125
4. Baumert Y, Lehmann R (1997) TIMMS: Mathematisch-naturwissenschaftlicher Unterricht im Internationalen Vergleich. Opladen: Leske und Budrich

5. Benbow CP (1988) Sex differences in mathematical reasoning ability in intellectually talented preadolescents: Their nature, effects, and possible causes. Behavioral and Brain Sciences 11: 169-232

6. Benson DF, Geschwind N (1970) Developmental Gerstmann syndrome. Neurology 20: $293-298$
7. Benton AL (1987) Mathematical disability and the Gerstmann syndrome. In: Deloche G, Seron X (eds) Mathematical Disabilities. A cognitive neuropsychological perspective. Hillsdale, New Jersey: Erlbaum

8. Brandys CF, Rourke BP (1991) Differential memory abilities in reading- and arithmetic-disabled children. In: Rourke BP (ed) Neuropsychological Validation of Learning Disability Subtypes. New York: Guilford Press 
9. Campbell JID, Clark JM (1988) An encoding complex view of cognitive number processing: comment on McCloskey, Sokol, and Goodman (1986). Journal of Experimental Psychology: General 117: 204-214

10. Dahmen W, Hartje W, Büssing A, Sturm W (1982) Disorders of calculation in aphasic patients. Spatial and verbal components. Neuropsychologia 20: 145-153

11. De Corte E, Verschaffel L (1987) The effect of semantic structure on first graders strategies for solving addition and subtraction word problems. J Res Mathematics Education 18: 363-381

12. Dehaene S (1992) Varieties of numerical abilities. Cognition 44: 1-42

13. Dehaene S, Spelke E, Pinel P, Stanescu R, Tsivkin S (1999) Sources of mathematical thinking: behavioural and brain-imaging evidence. Science 284: 970-973

14. Dellatolas G, von Aster MG, Willadino Braga L, Meier M, Deloche G (2000) Number processing and mental calculation in school children aged 7 to 10 years: a transcultural comparison. European Child and Adolescent Psychiatry (Suppl) (this issue)

15. Deloche G, Willmes K (2000) Cognitive neuropsychological models of adult calculation and number processing: on the role of the surface format of numbers. European Child and Adolescent Psychiatry (Suppl) (this issue)

16. Deloche G, Seron X, Larroque C, Magnien C, Metz-Lutz MN, Noel MN, Riva I, Schils JP, Dordain M, Tzavaras A, Vendrell J, Bergego C (1994) Calculation and number processing: assessment battery; role of demographic factors. Journal of Clinical and Experimental Neuropsychology 16: 195-208

17. Deloche G, von Aster MG, Dellatolas G, Gaillard F, Tièche C, Azema D (1995) Traitement des nombres et calcul en CE 1 et CE 2. Approche Neuropsychologique des Apprentissages chez l'Enfant (A.N.A.E.), Hors Série, 42-52

18. Deloche G (1995) EC301R: Batterie standardisée d'evaluation du calcul et du traitement des nombres. Salvador: Editora Sarah Letras

19. Donlan C (ed) (1998) The Development of Mathematical Skills. East Sussex: Psychology Press

20. Esser G (1991) Was wird aus Kindern mit Teilleistungsschwächen? Der langfristige Verlauf umschriebener Entwicklungsstörungen. Stuttgart: Enke

21. Esser G, Schmidt MH (1994) Children with specific reading retardation - early determinants and long-term outcome. Acta Paedopsychoatrica 56: 229-239
22. Fodor JA (1983) The Modularity of Mind. Cambridge: MIT Press

23. Fuson KC, Richards J, Briars DJ (1982) The acquisition and elaboration of the number word sequence. In: Brainerd CJ (ed) Children's Logical and Mathematical Cognition: Progress in Cognitive Developmental Research (pp 33-92). New York: Springer Verlag

24. Geary DC (1994) Children's Mathematical Development. Washington DC: American Psychological Association

25. Geary DC (2000) From infancy to adulthood: the development of numerical abilities. European Child and Adolescent Psychiatry (Suppl) (this issue)

26. Gelman R, Gallistel CR (1978) The Child's Understanding of Number. Cambridge, Mass: Harvard University Press

27. Grigsby JP, Kemper MB, Hagermann RJ (1987) Developmental Gerstmann syndrome without aphasia in fragile $\mathrm{X}$ syndrome. Neuropsychologia 25: 881-891

28. Gross-Tsur V, Shalev RS, Manor O, Amir N (1995) Developmental right hemisphere syndrome: clinical spectrum of the non-verbal learning disability. Journal of Learning Disabilities 28: 80-86

29. Gross-Tsur V, Manor O, Shalev RS (1996) Developmental dyscalculia: Prevalence and demographic features. Developmental Medicine and Child Neurology 38: 25-33

30. Halpern DF (1997) Sex differences in intelligence. American Psychologist 52: 1091-1102

31. Haskell SH (2000) The determinants of Arithmetic skills in young children: Some observations. European Child and Adolescent Psychiatry (Suppl) (this issue)

32. Hembree R (1990) The nature, effects and relief of mathematics anxiety. Journal of Research in Mathematics Education 21: $33-46$

33. Husen T (1967) International Study of Achievement in Mathematics: A Comparison of Twelve Countries. Vol 2. Stockholm: Almquist \& Wiksell

34. International Association for the Evaluation of Education Achievement (IEA) (1996) Mathematics Achievement in the Middle School Years: IEA's Third International Mathematics and Science Study (TIMSS). Chestnut Hill: Boston college

35. Karmiloff-Smith A (1992) Beyond Modularity. Cambridge: MIT Press

36. Kim KH, Relkin NR, Lee KM, Hirsch J (1997) Distinct cortical areas associated with native and second languages. Nature, 388: $171-174$

37. Kinsbourne M (1968) Developmental Gerstmann syndrome. Pediatric Clinics of North America 15: 771-778
38. Klauer KJ (1992) In Mathematik mehr leistungsschwache Mädchen, im Rechnen und Rechtschreiben mehr leistungsschwache Jungen? Zur Diagnostik von Teilleistungsschwächen. Zeitschrift für Entwicklungspsychologie und Pädagogische Psychologie 24: 48-65

39. Klin A, Volkmar FR, Sparrow SS, Cicchetti DV \& Rourke BP (1995) Validity and neuropsychological characterisation of Asperger Syndrome: convergence with nonverbal learning disability syndrome. Journal of Child Psychology and Psychiatry and Allied Disciplines 36: 1127-1140

40. Kopera-Frye K, Dehaene S, Streissguth AP (1996) Impairments of number processing induced by prenatal alcohol exposure. Neuropsychologia 34: 1187-1198

41. Kosc L (1974) Developmental dyscalculia. Journal of Learning Disabilities 7: 164-177

42. Mattson AJ, Sheer DE, Fletcher JM (1993) Electrophysiological evidence of lateralised disturbances in children with learning disabilities. Journal of Clinical and Experimental Neuropsychology 14: $707-$ 716

43. Mc Closkey M, Caramazza A, Basili A (1985) Cognitive mechanisms in number processing and calculation: evidence from dyscalculia. Brain and Cognition 4: 171196

44. Miura JT, Kim CC, Chang C-M, Okamoto Y (1988) Effects of language characteristics on children's cognitive representation of number: cross-national comparisons. Child Development 59: 1445-1450

45. Miura JT, Okamoto Y, Kim CC, Chang C-M, Steere M, Fayol M (1994) Comparisons of children's cognitive representation of number: China, France, Japan, Korea, Sweden and the United States. International Journal of Behavioral Development 17: 401-411

46. Morris HH, Lüders H, Lesser RP, Dinner DS, Hahn JH (1984) Transient neuropsychological abnormalities (including Gestmann's syndrome) during cortical stimulation. Neurology 34: 877-883

47. Ozols EJ, Rourke BP (1988) Characteristics of young learning-disabled children classified according to patterns of academic achievement: auditory-perceptual and visual-perceptual disabilities. Journal of Clinical Child Psychology 17: 44-52

48. PeBenito R (1987) Developmental Gerstmann syndrome: case report and review of the literature. Journal of Developmental Behavioral Pediatrics 8: 229-232 
49. Poeck K, Orgass B (1975) Gerstmann syndrome without aphasia: comments on the paper by Strub and Geschwind. Cortex 11: 291-295

50. Reusser K (2000) Success and failure in school mathematics: effects of instruction and school environment. European Child and Adolescent Psychiatry (Suppl) (this issue)

51. Rourke BP (1989) Nonverbal Learning Disabilities. The Syndrome and the Model. New York: Guilford Press

52. Rourke BP (1993) Arithmetic disabilities, specific and otherwise: a neuropsychological perspective. Journal of Learning Disabilities 26: 214-226

53. Rourke BP \& Finlayson MAJ (1978) Neuropsychological significance of variations in patterns of academic performance: verbal and visual-spatial abilities. Journal of Abnormal Child Psychology 6: 121-133

54. Rourke BP, Fuerst DR (1991) Learning Disabilities and Psychosocial Functioning. New York: Guilford Press

55. Rourke BP, Strang JD (1978) Neuropsychological significance of variations in patterns of academic performance: motor, psychomotor, and tactile-perceptual abilities. Journal of Pediatric Psychology 3: 62-66

56. Schwank I (1990) Untersuchungen algorithmischer Denkprozesse bei Mädchen. Osnabrück: Forschungsinstitut für Mathematikdidaktik

57. Schwank I (1992) Cognitive Structures and Cognitive Strategies in Algorithmic Thinking. Osnabrück: Forschungsinstitut für Mathematikdidaktik

58. Shalev RS, Gross-Tsur V (1993) Developmental dyscalculia and medical assessment. Journal of Learning Disabilities 26: 134-137
59. Shalev RS, Auerbach J, Gross-Tsur V (1995) Developmental dyscalculia: attentional and behavioral aspects. Journal of Child Psychology and Psychiatry 35: 1261-1268

60. Share DL, Moffit TE, Silva PA (1988) Factors associated with arithmetic and reading disability and specific arithmetic disability. Journal of Learning Disabilities 21: $313-320$

61. Slade PD, Russel GFM (1971) Developmental dyscalculia: a brief report on four cases. Psychological Medicine 1: 292-298

62. Spellacy F, Peter B (1978) Dyscalculia and elements of the developmental Gerstmann syndrome in school children. Cortex 14: 197-206

63. Starkey P, Spelke ES, Gelman R (1990) Numerical abstraction by human infants. Cognition 36: 97-127

64. Strang JD, Rourke BP (1983) Conceptformation / non-verbal reasoning abilities of children who exhibit specific academic problems with arithmetic. Journal of Clinical Child Psychology 12: 33-39

65. Temple C (1989) Digit dyslexia: a category-specific disorder in developmental dyscalculia. Cognitive Neuropsychology 6 : 93-116

66. Temple C (1997) Developmental Cognitive Neuropsychology. East Sussex: Psychology Press

67. Tiedemann J, Faber G (1995) Mädchen im Mathematikunterricht: Selbstkonzept und Kausalattributionen im Grundschulalter. Zeitschrift für Entwicklungspsychologie und Pädagogische Psychologie 27: 61-71

68. Towse J, Saxton M (1998) Mathematics across national boundaries: cultural and linguistic perspectives on numerical competence. In: Donlan C (ed) The Development of Mathematical Skills. East Sussex: Psychology Press
69. von Aster MG (1993) Developmental and acquired dyscalculias in children. In Stachowiak FJ (ed) Developments in the Assessment and Rehabilitation of Braindamaged Patients. Tübingen: Narr

70. von Aster MG (1994) Developmental dyscalculia in children: review of the literature and clinical validation. Acta Paedopsychiatrica 56: 169-178

71. von Aster MG (1996) Psychopathologische Risiken bei Kindern mit umschriebenen schulischen Entwicklungsstörungen. Kindheit und Entwicklung 5: 53-59

72. von Aster MG (1997) Die Störungen des Rechnens und der Zahlenverarbeitung in der kindlichen Entwicklung. Unveröffentlichte Habilitationsschrift. Universität Zürich

73. von Aster MG, Deloche G, Dellatolas G, Meier M (1997) Number processing and calculation in $2^{\text {nd }}$ and $3^{\text {rd }}$ grade school children: a comparative study of Frenchspeaking and German-speaking children. Zeitschrift für Entwicklungspsychologie und Pädagogische Psychologie 24: 151166

74. World Health Organization (1992) The ICD-10 Classification of Mental and Behavioral Disorders - Clinical Descriptions and Diagnostic Guidelines. WHO, Geneva

75. Witelson SF (1979) Geschlechtsspezifische Unterschiede in der Neurologie der kognitiven Funktionen und ihre psychologischen, sozialen, edukativen und klinischen Implikationen. In: Sullerot EE (Ed) Die Wirklichkeit der Frau. München: Steinhausen 